\title{
What clinicians need to know before assessing risk in sexual offenders ${ }^{\dagger}$
}

\author{
Rajan Darjee \& Katharine Russell
}

\begin{abstract}
SUMMARY
This article covers what clinicians need to know before undertaking a risk assessment of a sexual offender. It discusses general information about sexual offenders (characteristics, aetiological models, recidivism rates and legal responses); the association between mental disorders and sexual offending; risk and protective factors; and risk assessment tools.
\end{abstract}

\section{DECLARATION OF INTEREST}

None.

Rarely a week goes by without a media story about the dangers posed by sexual offenders; no other group is subject to the same degree of societal fear, hatred and disgust, and these dominate political debate. Psychiatrists and other mental health professionals are not immune from such influences. Although it may be difficult to remain unaffected by our own anxieties and moral judgement, and by societal pressure and political sensitivities, the primary task when working with someone who poses a risk of sexual offending is to use clinical skills and research evidence to understand the individual, objectively assess risk and develop a plan that mitigates this while helping the individual to function prosocially. The good news for clinicians is that there is research evidence as well clinical experience and guidance that can help with this.

In this article and its companion, we aim to help practitioners set up the pragmatic and evidencebased approach which our service has been using for over 5 years to inform the management of sexual offenders in the community. First, we will focus on the information clinicians need to know about sexual offenders before they assess risk and plan risk management. In the next article, we will discuss how to assess risk and develop a risk management plan.

Our main focus will be adult males. Although most sexual offenders are male, there is increasing recognition of female perpetrators (Gannon 2010), and a significant minority of sexual offences are committed by children and adolescents (Poortinga 2009). Space does not allow us to cover these groups in detail here, and it is important to note that approaches used for men should not be used for women or young people.

\section{Characteristics of sexual offenders and sexual offences}

Sexual offending covers behaviours ranging from sexual homicide, through rape and sexual touching, to indecent exposure and voyeurism. Whether behaviour is an offence or abusive depends on whether the victim is able and willing to consent. All sexual behaviour with children is abusive and illegal, although various ages define this in different countries. Coercion ranges from subtle manipulation, through threats, to holding victims down, and sometimes life-threatening violence. Recently there has been a rise in internet child pornography offences and increasing concern about the use of social networking websites to groom children for sexual abuse (Quayle 2008; Elliot 2009). Possession of extreme pornography (depicting bestiality, necrophilia or severely sadistic acts) is now illegal in the UK. A significant minority of sexual offences are committed by individuals acting together, ranging from pairs of offenders, through gangs and groups, to so-called 'paedophile rings'. Given the range of sexually abusive behaviour, it follows that sexual offenders are heterogeneous in motivations, circumstances, personal characteristics, personality, psychopathology, sexual functioning, propensity to reoffend and responsiveness to interventions.

Despite this heterogeneity there seem to be characteristics, motivations and pathways to offending common to some sexual offenders. Motivational typologies have been described for rapists (Knight 1990), child molesters (Knight 1990), exhibitionists (Morin 2008), internet offenders (Beech 2008), sexual murderers (Proulx 2007) and female offenders (Gannon 2010). Few have been empirically validated and individuals should not be squeezed into typological boxes; but typologies can help case formulation. For example, rapist typologies point to sadistic, angry, opportunistic and sexual types (Groth 1979; Canter 1990; Knight 1990; Kocsis 2006), although some have mixed motivations and not all rapists in any category are identical.
Rajan Darjee is a consultant forensic psychiatrist and Katharine Russell a consultant forensic clinical psychologist, and co-lead of the NHS Lothian Sex Offender Liaison Service, which offers consultation, assessment and treatment to help criminal justice and other agencies manage complex sexual offenders in the community. Clinical and research interests are paraphilias and personality disorders in sex offenders, and their implications for risk management in the community. Correspondence Rajan Darjee, NHS Lothian Sex Offender Liaison Service (SOLS), The Orchard Clinic, Royal Edinburgh Hospital, Morningside Terrace, Edinburgh EH10 5HF, UK. Email: rajan.darjee@ nhslothian.scot.nhs.uk

This is the first of two articles in Advances by Rajan Darjee and Katharine Russell that discuss the clinical assessment and management of risk in sexual offenders. The next will appear in the January 2013 issue. 


\section{What causes sexual offending?}

There are various aetiological theories of sexual offending (Ward 2006). Some single-factor theories highlight cognitive processes, deficient victim empathy, sexual deviance, biological factors or sociocultural issues. The most useful, given the complexity of sexual offending, are multifactor theories. Various models emphasise more distal (e.g. genetic and childhood development) and proximal (e.g. thinking and fantasising about offending) factors, and some describe 'pathways' to offending by combining various factors.

There are various aetiological models for rapists (Malamuth 1996) and child molesters (Ward 2002). Some offer broad frameworks for the development and maintenance of sexual offending generally (Marshall 1990; Ward 2008). In Ward \& Beech's (2008) unified theory, genetic and neurodevelopmental factors (through brain development) and the personal, sociocultural and physical environment shape psychological functioning (motivation/emotion, action/control and perception/memory). This underpins and leads to the development of factors (emotional problems, social difficulties, deviant arousal and/ or cognitive processing) more proximal to sexual offending. The consequences of offending then lead to maintenance, entrenchment and escalation of psychological traits through their impact on the offender's environment. This framework fits with current models of risk (Beech 2004), and mental disorders play a role at various points in this model.

Another framework that can be useful in clinical formulation is Hudson \& Ward's (2000) differentiation between approach offenders (who want to offend and feel positive after offending) and avoidant offenders (who try not to reoffend, have poor coping skills and experience negative affect after offending).

\section{Reoffending rates}

Ten to twenty per cent of sexual offenders commit further sexual offences over 5-10 years (Hanson 1998; Craig 2008). In a meta-analysis of recidivism in persistent sexual offenders, over an average follow-up period of 5-6 years (Hanson 2005 ) sexual recidivism was recorded for $13.7 \%$ of individuals, non-sexual violent recidivism for $14.0 \%$, violent recidivism (sexual or non-sexual) for $25.0 \%$ and general recidivism for $36.9 \%$. Offenders with adult victims have higher rates of violent and general recidivism than offenders against children. Sexual recidivism is highest in extra-familial child molesters, lowest in intra-familial child molesters and intermediate in adult rapists (Hanson 2002). Sexual offenders against male children recidivate more than those against females. Offenders with adult and child victims, or with male and female victims, recidivate more than 'non-diverse' offenders (Heil 2008). Female sexual offenders have very low recidivism (Sandler 2009). There are high rates of reoffending in men who indecently expose (Murphy 2008). About a fifth of sexual reoffending occurs more than 10 years after release (Home Office 2004). There are very low rates of new offences in sexual offenders after the age of 60 (Hanson 2002).

Unsurprisingly, higher rates of 'recidivism' are reported if non-convicted allegations or concerning behaviours are included (Falshaw 2003). Even taking into account underreporting, most sexual offenders do not reoffend; when they do, they usually commit non-sexual offences and they have lower recidivism rates than almost all other offender groups (Home Office 2001).

\section{Legal restrictions and measures}

In the UK, a range of legal restrictions can be applied to sex offenders in the community. The most common is the use of sex offender notification requirements, sometimes called signing the Sex Offenders Register (SOR) or being a registered sex offender (RSO). During the notification period individuals must inform the police of their address and any planned moves and they must report at least once a year giving certain personal details and information. The length of the notification period is determined by the sentence imposed. The police can use sexual offence prevention orders (SOPOs) and risk of sexual harm orders (ROSHOs) to restrict the behaviour of offenders if they believe that the offender poses a sexual risk to the public. Foreign travel orders (FTOs) can also be sought to prevent sex offenders from travelling to other countries. These orders are civil orders which are imposed by courts on application, but breaches may result in imprisonment.

Court disposals include indeterminate sentences, such as the order for lifelong restriction (ORL) in Scotland and imprisonment for public protection (IPP) in England andWales (McSherry 2009; Darjee 2011). An extended sentence may be added to a determinate sentence to allow a prolonged period of mandatory supervision subject to potential recall to prison. Indeterminate and extended sentences are used frequently for sex offenders. Probation, now known as a community payback order in Scotland, can be used as a community sentence, with conditions such as attendance at supervision and treatment and restrictions on what the person can do. Breach of probation may result in a jail sentence. Similarly, when offenders are released from prison on licence they will have parole 
conditions placed on them, and if they breach these, they can be recalled to prison to complete their sentence. Attending a sex offender treatment programme or receiving psychiatric treatment could be a condition of parole.

\section{Mental disorder and sexual offending}

It emerges that most sexual offenders have mental disorders when one considers the broad range of disorders in ICD-10 and DSM-IV. Most commonly encountered are personality disorders, paraphilias and substance-related disorders. Severe mental illnesses, organic disorders and intellectual disability are less common, but more prevalent than in the general population. Epidemiological research from Sweden (Fazel 2007) and Denmark (Alden 2007) questions the long-held view that there is no relationship between mental illness and sexual offending, in a way reminiscent of similar research on non-sexual violence in the 1990s. The relationship between mental disorder and sexual offending is complex. It may be mediated directly through symptoms, through the impact of disorder on interpersonal and sexual functioning, through secondary problems (substance misuse, poor social circumstances), or via other associations (e.g. personality dysfunction). Factors entirely unrelated to mental disorder will be important, and mental disorder may play a peripheral role in an individual case. The clinical task is to understand sexual offending in an individual, teasing out the functional relationship (direct and indirect) between disorder and behaviour. Psychiatrists should be wary of using mental disorder as the primary explanation for sexual offending or on the other hand dismissing entirely the role of a disorder. In most cases there is a complex interaction of disorder and non-disorder factors. Having understood the role of mental disorder, consideration should be given to the implications for risk assessment and management.

\section{Psychosis}

Schizophrenia and other psychoses are modestly associated with sexual offending, particularly less serious offending (Alden 2007; Fazel 2007). Comorbid personality disorder and substance misuse strengthen this association and are associated with more serious offending. In serious sexual offenders with schizophrenia in England and Wales who attacked adult females (Smith 1999a-d, 2000a,b): most had delusions or hallucinations related to offending, but few had symptoms which drove their offending; most were opportunistic or sexually motivated (rather than motivated by anger or sadism); bizarre or extreme behaviour was uncommon; most had interpersonal, emotional and sexual problems found commonly in non-mentally ill offenders, particularly those who offended before illness onset; and very few received psychological treatment to address sexual offending. Positive symptoms, negative symptoms, cognitive deficits, poor social functioning and medication affect various areas of psychosocial functioning of relevance to sexual offending (Drake 2006). Psychotic illness does not predict recidivism in long-term studies (Mann 2010). Nevertheless, in sexual offenders with psychosis, the potential role of illness-related factors underpinning stable dynamic factors and acting as acute precipitating factors (e.g. lack of adherence, relapse in mental state) needs to be considered, alongside non-illnessrelated factors.

\section{Affective and neurotic disorders}

Bipolar disorder and depression are less strongly related to sexual offending than schizophrenia (Alden 2007; Fazel 2007), but there is nevertheless a significant association. In some clinical samples, high rates of depression have been reported (Raymond 1999; Dunsieth 2004). Comorbid personality disorder and substance misuse increase this association. Mania causes sexual disinhibition, recklessness and grandiosity, which may lead to sexual offending, usually relatively minor in nature. Depression is associated with decreased libido, but some individuals use sexual fantasy and behaviour to cope with subclinical low mood, which may then precipitate offending. The presence of mood disorders does not predict sexual reoffending in the long term (Mann 2010), but changes in mood may be important proximal precipitants. Antidepressants may have sexual side-effects which decrease sexual behaviour or sometimes cause paradoxical problems. For example, anorgasmia may mean that a person spends more time masturbating, and impotence may lead them to devise more stimulating and deviant fantasies.

Anxiety disorders have a modest positive association with sexual offending (Fazel 2007). Poor coping with stress and anxiety are important factors in some sexual offenders, and some cope with stress by using sexual fantasy and behaviour.

Sexual obsessions are not uncommon in obsessive-compulsive disorder, but are not associated with sexual offending. Some clinicians have pointed to similarities between paraphilias and obsessive-compulsive disorder, particularly where sexual fantasies, urges and behaviours appear to be ego-dystonic; but phenomenologically, sexual obsessions are distinct from sexual fantasies - sexual obsessions are not associated with sexual arousal. 


\section{Organic disorders and intellectual disability}

Organic psychoses are associated with sexual offending (Alden 2007). Dementia may lead to sexually offensive behaviour through disinhibition, deterioration in personality and cognitive decline. Sexual disinhibition may occur with frontal pathology. Delirium may precipitate disorganised impulsive sexual behaviour. Elevated rates of intellectual disability have been reported in sexual offenders (Griffiths 2009). For example, some individuals with autism spectrum disorders commit sexual offences. Poor perspective-taking, poor social and interpersonal skills, repetitive preoccupations and isolation may play a role. However, caution needs to be exercised in interpreting findings, as individuals with intellectual disability may be both more likely to be detected and less likely to live in situations where they are afforded privacy for sexual behaviour.

Many sexual offenders with intellectual disability are diverted to health or social care and not convicted. High rates of sexual offending in this group may reflect repressive and restrictive attitudes towards sexuality in people with intellectual disabilities. Impaired social functioning, poor interpersonal and intimacy skills and lack of sexual knowledge may impair their ability to manifest sexuality appropriately. However, some sexual offenders with intellectual disability do not have such problems and are similar in background and characteristics to sex offenders without intellectual disability.

Having an intellectual disability is not in itself associated with recidivism. As with any intervention for people with intellectual disability, it is important that treatment programmes are delivered so as to take into account intellectual deficits.

\section{Personality disorder}

Very high rates of personality disorders have been reported in sexual offenders (Fazel 2007; Craissati 2008). Personality disorder is particularly prevalent in high-risk sexual offenders on long or indeterminate sentences (Coid 2007), and among difficult-to-manage sexual offenders in the community (Ministry of Justice National Offender Management Service 2011). Personality pathology is heterogeneous. High rates of antisocial, narcissistic, paranoid and psychopathic traits have been described in adult rapists, with higher rates of avoidant, schizoid and obsessional traits in child and internet offenders. High rates of borderline personality disorder have also been reported. Psychopathy is associated with violent recidivism but not specifically with sexual recidivism (Dematteo 2010). A number of stable dynamic risk factors (see Risk and protective factors, below) are manifestations of dysfunctional personality traits. It is important to understand the personality pathology of a sexual offender when assessing risk, planning management and delivering treatment.

\section{Sexual disorders}

Unsurprisingly, paraphilias are associated with sexual offending. But not all sex offenders have paraphilias, and most people with paraphilias do not commit offences (Federoff 2009). Rates of paraphilias in sex offenders of between 25 and $75 \%$ have been reported (Raymond 1999; Dunsieth 2004; Hanson 2007). In child molesters, extra-familial offenders have high rates of paedophilia, but most incest offenders are not paedophilic. Most rapists do not have paraphilias and very few are sexually sadistic. However, up to $80 \%$ of sexual murderers have paraphilias (Hill 2007; Proulx 2007).

Some sexual offenders have multiple paraphilias. Deviant sexual interests, particularly paedophilia, sexual sadism and multiple paraphilias, are associated with sexual recidivism. Other paraphilias probably increase the risk of reoffending in specific types of offenders (e.g. frotteurism in a man convicted of breach of the peace for rubbing himself against women on buses). Phallometric assessment of internet child pornography offenders shows that they have higher rates of paedophilia than contact offenders (Quayle 2008). Sexual dysfunctions, particularly erectile problems, are sometimes encountered. Hypersexual arousal (a suggested sexual dysfunction for DSM-5) is associated with reoffending. There does not appear to be an association between gender dysphoria and sexual offending.

\section{Implications for the role of mental health services}

Mental health services have a direct role to play in managing sexual offenders with mental illness, organic disorder and intellectual disability. When such individuals commit serious offences they are usually admitted to secure hospitals and later managed in the community by psychiatric services. As well as treating illness and improving social functioning, it is important that management involves an evidence-based assessment of risk and addresses factors of relevance to sexual offending, as outlined later and in our next article. Just 'treating the illness' will rarely address the risk of recidivism.

For sexual offenders with personality disorder and paraphilias, the appropriate system is the criminal justice system. However, in such cases the role of clinicians should be to provide consultation, assessment and treatment within the criminal justice context, either in prison or the community. Psychiatric assessments that conclude a person 
is 'not mentally ill' are not particularly helpful. Clinicians should be able to provide a clinical formulation and advice on management for these difficult cases. This is the model we use in the NHS Lothian Sex Offender Liaison Service, where we provide psychological and psychiatric input to support police offender management units and criminal justice social workers (the Scottish equivalent of probation officers) with complex cases (Russell 2012). It is also the model for working with offenders with personality disorder in the community, which is being promoted by the Ministry of Justice and Department of Health in England and Wales (Department of Health 2011).

\section{Risk and protective factors}

A sexual violence risk factor is a variable that is associated with future risk of sexual violence and/or will be important in managing this risk. A number of risk factors have been identified in the literature (Hanson 1998, 2000, 2005; Craig 2008; Cortoni 2009; Mann 2010). These can be divided into three groups (Box 1).

1 Historical/static risk factors are superficial markers of intrinsic and largely stable aspects of an individual, which in research samples have been shown to predict reoffending. They anchor any risk assessment and set the tone in terms of the risk a person poses in the long term.

2 Stable dynamic risk factors are emotional, interpersonal, cognitive, social and sexual problems, which are psychological aspects of an individual that may change slowly over time, perhaps in response to treatment. These factors should indicate why particular historical factors are pertinent in any case. Stable dynamic factors should help in understanding why a person has offended in the way they have done, in assessing response to treatment and interventions, and in guiding assessment of whether there has been underlying change in key areas of psychosocial functioning. Genetic predisposition, childhood experiences, adolescent development and significant events in adulthood will shape psychological, social and sexual functioning, i.e. determine the development of functioning in areas covered by stable dynamic risk factors.

3 Acute dynamic risk factors are indicative of the imminence of risk. Some are triggers (destabilisers, disinhibitors or precipitants) which act via stable dynamic factors to place someone in a situation or state where they are likely to reoffend; others are indicative of a situation or state of mind which means that they may be moving towards reoffending.
BOX 1 Historical/static, stable dynamic and acute dynamic risk factors for sexual reoffending

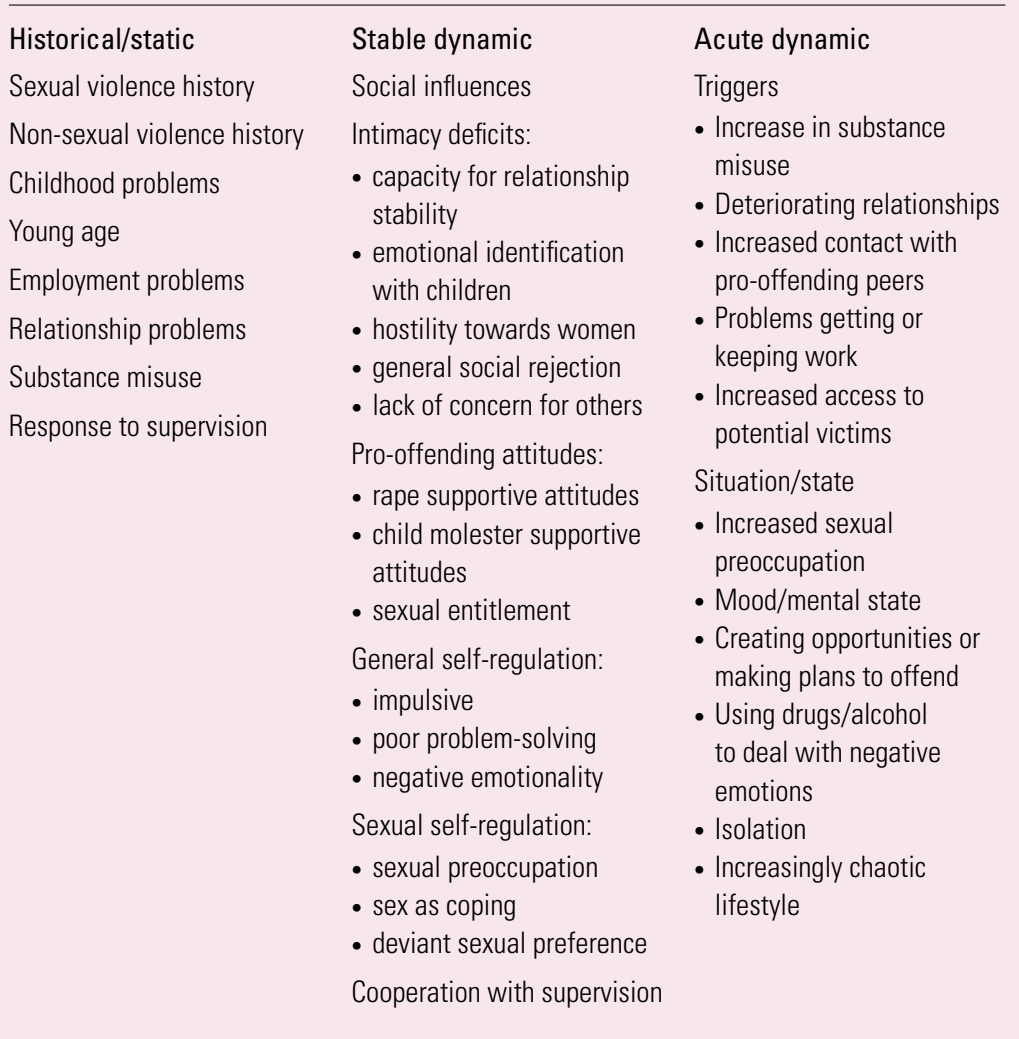

\section{Historical/static risk factors}

Historical/static factors fall into two broad categories: antisocial and sexual. Antisocial factors are associated with sexual and nonsexual recidivism, and sexual factors with sexual recidivism only. Examples of historical antisocial factors are: young age, employment problems, use of drugs and alcohol, childhood behavioural problems, non-sexual violence history, general offending history and breaches of supervision. Inability to form stable intimate relationships is a factor that encompasses both antisocial and sexual elements. Like employment problems, inability to form intimate relationships is a marker for a variety of underlying problems including impulsivity, emotional dysregulation, attachment problems or distorted attitudes towards women. Difficulties in non-intimate relationships is not a factor statistically related to sexual recidivism, but, as with intimate relationships, may be a marker for a number of stable dynamic factors.

In terms of sexual factors, having previous sexual offences and the number of these are associated with reoffending. The nature of the offences, degree of violence used, escalation and diversity in offending, victim type and use of physical and/ or psychological coercion are important areas to 
BOX 2 Evidence-based stable dynamic risk factors

\begin{tabular}{|c|c|c|}
\hline $\begin{array}{l}\text { Empirically supported } \\
\text { - Grievance/hostility } \\
\text { - Resistance to rules and } \\
\text { supervision } \\
\text { - Poor problem-solving } \\
\text { - Lifestyle impulsiveness } \\
\text { - Lack of emotionally } \\
\text { intimate relationships with } \\
\text { adults } \\
\text { - Sexual deviance } \\
\text { - Offence supportive } \\
\text { attitudes } \\
\text { - Sexualised violence } \\
\text { - Poor social influences }\end{array}$ & $\begin{array}{l}\text { Promising } \\
\text { - Hostility towards women } \\
\text { - Machiavellianism } \\
\text { - Callousness/lack of } \\
\text { concern for others } \\
\text { - Sexualised coping } \\
\text { - Externalised coping } \\
\text { Unsupported but with } \\
\text { interesting exceptions } \\
\text { - Denial } \\
\text { - View of self as inadequate } \\
\text { - Major mental illness } \\
\text { - Loneliness }\end{array}$ & $\begin{array}{l}\text { Worth looking at } \\
\text { - Adversarial sexual } \\
\text { attitudes } \\
\text { - Fragile narcissism } \\
\text { - Sexual entitlement } \\
\text { Not risk factors } \\
\text { - Depression } \\
\text { - Social skills deficits } \\
\text { - Victim empathy } \\
\text { - Motivation for treatment, } \\
\text { as assessed pre-treatment }\end{array}$ \\
\hline
\end{tabular}

consider. Having male victims (particularly where victims are children), a history of non-contact offending, offending against unrelated or stranger victims, victims of both genders, and both adult and child victims are related to sexual recidivism. Statistically, the degree of injury caused to victims is inversely related to the likelihood of recidivism, but the degree of harm to victims is important when assessing the potential for serious harm.

\section{Stable dynamic/dispositional risk factors}

Stable dynamic factors (Box 1) have been identified and described by Hanson $\&$ Harris (2000) and Beech et al (2003). They can be divided into four categories:

1 sexual interests/sexual self-regulation

2 attitudes

3 socio-affective functioning

4 general self-regulation.

They are relatively stable over time, but amenable to change through treatment and time, in the medium to long term. They are the most important things to focus on in treatment and when looking for underlying change of longer-term significance.

Mann et al (2010) described these factors as 'psychologically meaningful [...] propensities' that may or may not manifest at a point in time. Most static factors are just markers for these more meaningful factors (e.g. "number of sexual offences against young boys' is a marker for 'sexual deviance'). Mann et al define 'psychologically meaningful risk factors' as having: (a) a plausible rationale that the factor causes sexual offending; and (b) strong evidence that it predicts sexual recidivism. They used the second of these criteria to look at the strength of evidence supporting the use of various factors, separating them out into five categories (Box 2):
1 empirically supported

2 promising

3 unsupported but with interesting exceptions

4 worth looking at

5 not risk factors.

Although there is evidence for the risk factors discussed below, their causal role is yet to be identified. Also, no one factor is strongly statistically related to recidivism, so no factor can be used in isolation and factors must be combined when assessing risk.

\section{‘Empirically supported' risk factors}

Empirically supported factors (at least three studies have shown a significant association with sexual recidivism when meta-analytically integrated) include those associated with general or violent offending (e.g. lifestyle impulsiveness and poor problem-solving). However, there are specific factors associated with sexual offending (e.g. emotional congruence with children, multiple paraphilias and sexual preference for pubescent or pre-pubescent children). These factors tap into the sexual functioning problems that make a person more likely to sexually offend.

\section{'Promising' risk factors}

Within the 'promising' category (one study shows significant predictive value and other kinds of supportive evidence), Machiavellianism, the tendency to manipulate and deceive others for personal gain, may be less well known (Thornton 2003). It is a trait associated with psychopathy. Psychopathy itself is not used by Mann et al, but several of the factors they list are psychopathic traits (e.g. lack of concern for others, Machiavellianism, offence supportive attitudes, resistance to rules and supervision). Their inclusion is not surprising given the evidence that psychopathy is associated with recidivism (Hare 2006; Dematteo 2010). Where psychopathy is associated with sexual deviance, there is a particularly high risk of serious sexual and violent recidivism (Olver 2006). Hostility towards women is of relevance in men who rape women. Studies have shown it to be related to acts of sexual aggression (Malamuth 1991) and sexual recidivism (Hanson 2007). Dysfunctional coping is a wellestablished risk factor for reoffending generally; in sex offenders, Mann et al (2010) highlight sexualised coping and externalised coping.

\section{Risk factors that are 'Unsupported, but with} interesting exceptions'

In this category, denial has not been found to be related to recidivism and may actually be protective in high-risk cases. Two studies found 
that denial was associated with recidivism in lowrisk incest offenders (Nunes 2007; Harkins 2010), but confirmed that, in general, denial should not be considered a risk factor (Hanson 1998, 2005; Langton 2008). Denial is common in sex offenders and occurs for various reasons (e.g. shame, to preserve social contacts, to preserve self-esteem, lack of self-awareness). Denial and minimisation are often cited as risk factors, due to 'common sense', gut feelings and tradition. None of these are good reasons, and denial is usually unimportant as a risk factor. However, denial may influence whether an individual engages in treatment and other aspects of management, and so needs to be taken into account when planning interventions.

Major mental illness is not associated with longterm recidivism, but symptoms of mental illness, and impact of mental illness on social and emotional functioning may play a role, perhaps as more acute factors, in both sexual and non-sexual recidivism. Low IQ and intellectual disability do not predict sexual recidivism, but may be related to non-sexual recidivism. However, deficits in interpersonal and social functioning and lack of sexual knowledge may be relevant factors in some cases. Loneliness has not been found to be important in metaanalytic studies, but was associated with recidivism in one study (Hanson 2007). Mann et al (2010) recommended further research to identify when it becomes important. Low self-esteem did not predict recidivism in the Hanson $\&$ Morton-Bourgon (2005) meta-analysis, but British studies showed it did (Thornton 2004). The reason for this is unclear, but could be due to a cultural difference.

\section{Risk factors that are 'Worth looking at'}

Factors with potential to be psychologically meaningful, but requiring further exploration, the 'worth looking at' category, include: adversarial sexual orientation (Malamuth 1991); fragile narcissism, which has been associated with aggression in response to threats to a grandiose selfimage (Bushman 1998; Papps 1998; Stuker 2002); and sexual entitlement (Hanson 1994, 2007).

\section{'Not risk factors'}

Victim empathy is in the 'not a risk factor' category. Although there is significant evidence to support this assertion (Hanson 2005), it remains controversial. It seems to make sense that lack of victim empathy makes someone more risky. But this 'common sense' is based on our own emotional and moral reactions, not evidence. Victim empathy is a multifaceted concept which is heterogeneous and difficult to define, encompassing emotional, perceptual, cognitive and behavioural aspects (Marshall 2002).
Nonetheless, it has been a significant part of sex offender treatment programmes. It may be that what we assess as poor victim empathy is actually post hoc justifications. Although general lack of empathy for others (a trait of psychopathy) is associated with recidivism, lack of empathy for one's victims specifically does not appear to be.

Motivation for treatment is something we are notoriously poor at assessing. What is it we expect people to say pre-treatment to show they will be amenable to treatment? What is clear from research is that, like poor victim empathy, it is not an evidence-based risk factor for sexual recidivism. Our assessments of whether sex offenders are or are not motivated for treatment are irrelevant to risk.

\section{Acute factors}

Acute factors are proximal to an offence and indicate that offending may be imminent (Hanson 2000). The evidence base for acute factors is not strong, but it is difficult to research factors that act over minutes, hours or days. Based on our experience and practice, these proximal factors are important and make sense conceptually.

The following factors may act as triggers: escalation in alcohol or drug use; deteriorating intimate and non-intimate relationships; loss of social support; increased contact with antisocial or pro-sexual offending peers; loss of employment or problems at work; stress; access to potential victims through creating opportunities, change in circumstances or others being less vigilant.

The following may reflect the person's state of mind or a situation which makes sexual offending more imminent: sexual preoccupation (with deviant or non-deviant themes); mood/mental state (increasing anxiety, depression, hostility, frustration, psychotic symptoms); evidence that the person is planning to offend or making an opportunity to offend (e.g. carrying a weapon or driving around the streets); lack of cooperation with supervision or treatment (not turning up for appointments, not complying with conditions, poor behaviour in sessions); intoxication with alcohol or drugs as a dysfunctional way of coping with negative emotions; isolation; lifestyle becoming increasingly chaotic.

\section{Protective factors}

In addition to risk factors, it is important to consider protective factors. Unfortunately, there has been relatively little research on protective factors in sexual offending, and they rarely feature in risk assessment tools. A recent development has been the Structured Assessment of Protective Factors (SAPROF; de Vogel 2009), an instrument that helps with the identification and assessment 
of protective factors, which can be used alongside structured professional judgement risk assessment instruments (discussed below). A protective factor is not merely the absence of a risk factor, although the absence of certain risk factors (e.g. a history of sexual offending) in a general way indicates a relatively low likelihood of future offending.

There are two types of protective factors: personal strengths and external supports/controls. Personal strengths to consider include ability to: cope with stress and interpersonal conflict; form age-appropriate intimate relationships; and engage with others. Some strengths may be life-long, and some may develop with help, support and intervention. A key issue to consider is whether there is evidence that the person has the skills, ability and inclination to lead a pro-social life, meeting their needs (for relationships, occupation, friendship, self-worth, acquiring material goods) in a way that does not involve offending.

Beyond intrinsic strengths, external supports, relationships and circumstances may help the individual to not reoffend. Looking at periods of an offender's life where they have not offended and positive responses to previous management can help identify protective factors in a case. The literature on desistance from offending (i.e. the natural process by which a person turns away from offending and moves towards a pro-social life) provides useful pointers towards factors that may be protective in the longer term and things that we should promote when working with sexual offenders (Laws 2011).

\section{Identifying and combining risk factors: risk assessment instruments}

A number of risk assessment instruments for sexual offenders have been developed (Box 3). Indeed, there are probably more risk assessment instruments for sexual offending than all other types of offending combined. Risk assessment instruments aim to identify risk (and very occasionally protective) factors and combine them to determine the risk posed. There are various approaches which have their advocates and critics. Instruments fall into three categories: actuarial, dynamic and structured professional judgement.

Unstructured clinical judgement (e.g. 'In my opinion, based on $\mathrm{X}$ years of experience and my feel for this case...') lacks validity, reliability and transparency, and has nothing to recommend it. Anamnestic approaches (i.e. a functional analysis of previous offending patterns) are part of the structured professional judgement process, but have no evidence base on their own and assume that patterns of offending do not change.
Structured professional judgement approaches are most commonly used by mental health professionals in the UK. Clinicians may come across actuarial and dynamic risk assessment tools used by criminal justice agencies. It is useful to know how they work, how to interpret them and what their limitations are.

\section{Actuarial approaches}

Actuarial instruments use a limited number of historical static factors. Their development involves following up a sample and using statistical methods to identify and combine factors mathematically to best predict recidivism. Factors are weighted depending on their predictive strength. Only a few facts about a person are required. Advocates of the actuarial approach laud this scientific, objective and defensible approach to predicting recidivism (Quinsey 2006), but opponents argue that they tell you little or nothing about the individual and that a risk level based on group statistics does not help prevent offending through guiding risk management (Vincent 2009; Cooke 2011).

In long-term follow-up studies of groups of offenders, actuarial tools tend to perform better statistically than structured professional judgement tools, which in turn perform better than unstructured clinical judgement, which in most studies is no better than chance. If the person being assessed has little in common with the offenders in development or validation samples, the tool should not be used. These tools are also limited to longterm likelihood of recidivism and not other facets of risk such as nature, severity of harm, imminence or frequency of offending.

BOX 3 Sexual violence risk assessment instruments

Actuarial

- Risk Matrix 2000 (Thornton 2007)

- Static-99 (Hanson 1999)

- Sex Offender Risk Appraisal Guide (SORAG; Quinsey 2006)

Dynamic

- Stable and Acute 2007 (Hanson 2007)

- Structured Assessment of Risk and Needs (Webster 2006)

- Violence Risk Scheme - Sex Offender version (Wong 2010)

Structured professional judgement

- Sexual Violence Risk-20 (Boer 1997)

- Risk for Sexual Violence Protocol (RSVP; Hart 2003) 


\section{Dynamic approaches}

Dynamic risk assessment instruments identify and combine dynamic factors (stable and perhaps acute factors) rather than static ones, and can be used to inform treatment, monitor change over time and assess risk of recidivism. They have been developed from research on factors of relevance to sexual offending.

The best researched and validated dynamic tool is the Stable and Acute 2007 (Hanson 2007). Like static actuarial tools, this tool has been developed and validated in particular samples, and so should be used with caution in offenders who are unusual. The summation of scores for each factor gives a total score, which indicates a risk level. These levels improve on the use of static actuarial tools alone in predicting recidivism (Hanson 2001, 2007; Beech 2003; Olver 2011).

In practice, however, it is difficult to know how to combine the results of a static and dynamic tool in an individual case. If the assessor looks at the factors present rather than the 'total score', the tools are useful in identifying factors of relevance to treatment. The Structured Assessment of Risk and Needs is used in this way (as a structured professional judgement tool) rather than yielding a total score and risk level. It is important that those who use these assessments know their strengths and limitations, and have received appropriate training in their use and interpretation.

\section{Structured professional judgement approaches}

Structured professional judgement tools, also known as 'structured clinical judgement', 'structured clinical risk assessment' and 'structured professional guidelines', are developed from reviewing the research literature on factors related to recidivism. The evidence-based factors identified are listed with explicit criteria. The most commonly used structured professional judgement tool, which many clinicians are familiar with, is the Historical, Clinical, Risk Management-20 (HCR-20; Webster 1997) used for non-sexual violence. As these tools require clinical judgement, they are mainly used by clinicians (particularly psychologists and psychiatrists). The users of these tools are expected to possess certain clinical qualifications, to have knowledge, experience and training in forensic assessment and the type of risk under consideration, and to be up to date with the literature.

When initially introduced in the late 1990s, the structured professional judgement approach involved rating risk factors, adding scores and making a judgement about risk level. This approach has evolved significantly since then. The assessor considers whether each factor is present, partially present or absent (according to specified criteria), and then whether the factor is definitely, partially or not relevant to future risk management (through a relationship with either the behaviour of concern or responsivity to risk management). Risk factors are combined through formulation using clinical judgement, rather than in a predetermined fashion using a mathematical formula, as is done in actuarial assessment. Narrative risk scenarios are generated to outline how the offender may reoffend in the future, including information about the nature, severity, frequency and imminence of such offences, likely victims and the contexts when offending may occur. These scenarios are used to develop a management plan to mitigate risk. Last, consideration is given to case prioritisation (relative to other cases), whether there is a risk of serious physical harm and whether immediate action is necessary. The Sexual Violence Risk-20 instrument (SVR-20; Boer 1997) (Box 4) and the Risk for Sexual Violence Protocol (RSVP; Hart 2003) (Box 5) are the two most commonly used structured professional judgement tools for sex offenders (Hart 2010).

The key difference between the actuarial and the structured professional judgement approach is how risk factors are combined to form a risk conclusion. If a structured professional judgement tool is used as a pseudo-actuarial tool by adding up factor scores to give a total, it generally performs less well than an actuarial tool in predicting recidivism in the long-term. However, if SPJ tools are used in research as they are in clinical practice, not through adding scores but through generating a clinical judgement about risk, then they perform better (Heilbrun 2010).

It is worth noting that there has been little research on the reliability or validity of the risk scenarios generated using structured professional judgement

BOX 4 Items of the Sexual Violence Risk-20 (SVR-20)

\begin{tabular}{|c|c|c|}
\hline \multirow{3}{*}{$\begin{array}{l}\text { Psychosocial adjustment } \\
1 \text { Sexual deviation } \\
2 \text { Victim of child abuse }\end{array}$} & 10 Past violent offences & 16 Escalation in frequency \\
\hline & 11 Past supervision failure & rity of sex \\
\hline & & \\
\hline 3 Psychopathy & Sexu & 17 Extreme minimisation or \\
\hline Major mental illness & $\begin{array}{l}12 \text { High-density sex } \\
\text { offences }\end{array}$ & 18 Attitudes that support \\
\hline Substance use problems & 13 Multiple sex offence & condone sex offences \\
\hline 6 Suicidal/homicidal & & Futur \\
\hline $\begin{array}{l}\text { Ideation } \\
\text { Relationship problems }\end{array}$ & $\begin{array}{l}14 \text { Physical harm to } \\
\text { victim(s) in sex offences }\end{array}$ & 19 Lacks realistic plans \\
\hline Employment problems & 15 Uses weapons or & 20 Negati \\
\hline $\begin{array}{l}9 \text { Past non-sexual violent } \\
\text { offences }\end{array}$ & $\begin{array}{l}\text { threats of death in sex } \\
\text { offences }\end{array}$ & (Boer 19s \\
\hline
\end{tabular}


BOX 5 Items of the Risk for Sexual Violence Protocol (RSVP)

\begin{tabular}{ll}
\hline Sexual violence history & - Psychopathic personality disorder \\
- Chronicity & - Major mental illness \\
- Diversity & - Problems with substance misuse \\
- Escalation & - Violent or suicidal ideation \\
- Physical coercion & Social adjustment \\
- Psychological coercion & - Problems with intimate relationships \\
Psychological adjustment & - Problems with non-intimate relationships \\
- Extreme minimisation or denial & - Problems with employment \\
- Attitudes that support or condone sexual & - Non-sexual criminality \\
violence & Manageability \\
- Problems with self-awareness & - Problems with planning \\
- Problems with stress or coping & - Problems with treatment \\
- Problems resulting from child abuse & - Problems with supervision \\
Mental disorder & \\
- Sexual deviance &
\end{tabular}

approaches. Critics argue these approaches are mathematically inferior to (and at best no better than) actuarial approaches; they require resources, time and clinical experience; and the incorporation of clinical judgement, even within a structured approach, weakens their predictive validity. Proponents argue that structured professional judgement approaches provide an evidence-based individualised assessment, allowing for factors to be combined in different ways, offering flexibility and enabling consideration of unusual or complex cases, and that they help prevent offending through guiding the development of risk management plans.

\section{Conclusions}

We have attempted to give an overview of what clinicians need to know before assessing risk in a sexual offender. Despite the popular public stereotype of the dangerous predatory paedophile or rapist, sex offenders are heterogeneous and few fulfil these images. Although there are some commonalities between sex offenders (hence aetiological models, typologies and evidence-based risk factors), it is important to understand the particular factors in an individual case.

Most sexual offenders have mental disorders, particularly personality disorders, paraphilias and substance misuse, but also psychosis, affective disorders, neurotic disorders, organic disorders and intellectual disabilities. Clinicians need to understand the role of any mental disorder in sexual offending, and must consider factors unrelated to the disorder when assessing and managing risk.

Risk factors for sexual offending can be usefully divided into static, stable dynamic and acute. Most risk factors for sexual violence relate to antisociality or sexual problems. Victim empathy and denial are not evidence-based risk factors. Protective factors have been less well researched, but include personal strengths and extrinsic supports. Risk assessment instruments attempt to combine risk factors to provide a conclusion about risk. There are actuarial, dynamic and structured professional judgement instruments. Proponents of each make strong arguments for a particular approach and against others, but the important things when using any instrument are to be trained and qualified to use them, to know their strengths and limitations and to know how to interpret them. Structured professional judgement approaches are particularly useful for sexual offenders who are mentally disordered, complex or unusual.

In the next article we will set out how to use a structured professional judgement approach to assess risk and plan risk management.

\section{References}

Alden A, Brennan P, Hodgins S, et al (2007) Psychotic disorders and sex offending in a Danish birth cohort. Archives of General Psychiatry 64: $1251-8$.

Beech AR, Fisher D, Thornton D (2003) Risk assessment of sex offenders. Professional Psychology: Research and Practice 34: 339-52.

Beech AR, Ward T (2004) The integration of etiology and risk in sexual offenders: a theoretical framework. Aggression and Violent Behavior 10: 31-63

Beech AR, Elliot IA, Birdgden A, et al (2008) The internet and child sexual offending: a criminological review. Aggression and Violent Behavior 13: 216-28.

Boer DP, Hart SJ, Kropp PR, et al (1997) Manual for the Sexual Violence Risk - 20: Professional Guidelines for Assessing Risk of Sexual Violence. The Institute Against Family Violence.

Bushman BJ, Baumeister RF (1998) Threatened egotism, narcissism, self-esteem, and direct and displaced aggression: does self-love or self-hate lead to violence? Journal of Personality and Social Psychology 75: 219-29.

Canter DV, Heritage R (1990) A multivariate model of sexual offence behaviour: developments in offender profiling. Journal of Forensic Psychiatry 1: 185-212.

Coid J, Yang M, Ullrich S, et al (2007) Predicting and Understanding Risk of Reoffending: The Prisoner Cohort Study (Research Summary 6). Ministry of Justice.

Cooke D, Michie C (2011) Violence risk assessment: challenging the illusion of certainty. In Dangerous People: Policy, Prediction, and Practice (eds B McSherry, P Kezer): 147-63. Routledge.

Cortoni F (2009) Factors associated with sexual recidivism. In Assessment and Treatment of Sex Offenders (eds AR Beech, LA Craig, KD Browne): 39-52. Wiley-Blackwell.

Craig LA, Browne KD, Beech AR (2008) Assessing Risk in Sex Offenders: A Practitioner's Guide. John Wiley \& Sons.

Craissati J, Webb L, Keen S (2008) The relationship between developmental variables, personality disorder, and risk in sex offenders. Sexual Abuse: A Journal of Research and Treatment 20: 119-38.

Darjee R, Russell K (2011) The assessment and sentencing of high risk offenders in Scotland: a forensic clinical perspective. In Dangerous People: Policy, Prediction, and Practice (eds B McSherry, P Kezer): 217-32. Routledge.

Dematteo D, Edens JF, Hart A (2010) The use of measures of psychopathy in violence risk assessment. In Handbook of Violence Risk Assessment (eds RK Otto, KS Douglas): 19-40. Routledge. 
Department of Health, NOMS Offender Personality Disorder Team (2011) Consultation on the Offender Personality Disorder Pathway Implementation Plan. Department of Health.

Drake CR, Pathé M (2006) Understanding sexual offending in schizophrenia. Criminal Behaviour and Mental Health 14: 108-20.

Dunsieth Jr NW, Nelson EB, Brusman-Lovins LA, et al (2004) Psychiatric and legal features of 113 men convicted of sexual offences. Journal of Clinical Psychiatry 65: 293-300.

Elliot IA, Beech AR (2009) Understanding online child pornography use: applying sexual offence theory to internet offenders. Aggression and Violent Behavior 14: 180-93.

Falshaw L, Friendship C, Bates A (2003) Sex Offenders - Measuring Reconviction, Reoffending and Recidivism (Findings 183). Home Office.

Fazel S, Sjostedt G, Langstrom N, et al (2007) Severe mental illness and risk of sexual offending in men: a case-control study based on Swedish national registers. Journal of Clinical Psychiatry 68: 588-96.

Federoff JP (2009) The paraphilias. In New Oxford Textbook of Psychiatry (2nd edn) (eds MG Gelder, NC Andreasen, JL López-lbor, et al): 832-42. Oxford University Press.

Gannon TA, Cortoni F (2010) Female Sexual Offenders: Theory, Assessment and Treatment. Wiley-Blackwell.

Griffits D, Federoff JP (2009) Persons with intellectual disabilities who sexually offend. In Sex Offenders: Identification, Risk Assessment, Treatment and Legal Issues (eds FM Saleh, AJ Grudzinskas, JM Bradford, et al): 353-75. Oxford University Press.

Groth AN (1979) Men Who Rape: The Psychology of the Offender. Basic Books

Hanson RK, Gizzarelli R, Scott H (1994) The attitudes of incest offenders: sexual entitlement and acceptance of sex with children. Criminal Justice and Behavior 21: 187-202.

Hanson RK, Bussiere MT (1998) Predicting relapse: a meta-analysis of sexual offender recidivism studies. Journal of Consulting and Clinical Psychology 66: 348-62.

Hanson RK, Thornton D (1999) Static 99: Improving Actuarial Risk Assessments for Sex Offenders. User Report 1999-02. Department of the Solicitor General of Canada.

Hanson RK, Harris A (2000) Where should we intervene? Dynamic predictors of sexual offence recidivism. Criminal Justice and Behaviour 27: 6-35.

Hanson RK, Harris A (2001) A structured approach to evaluating change among sexual offenders. Sexual Abuse: A Journal of Research and Treatment 13: 105-22.

Hanson RK (2002) Recidivism and age: follow-up data from 4,673 sexual offenders. Journal of Interpersonal Violence 17: 1046-62.

Hanson RK, Morton-Bourgon KE (2005) The characteristics of persistent sexual offenders: a meta-analysis of recidivism studies. Journal of Consulting and Clinical Psychology 73: 1154-63.

Hanson RK, Harris AJR, Scott T, et al (2007) Assessing the Risk of Sexual Offenders on Community Supervision: The Dynamic Supervision Project. User Report 2007-05. Department of the Solicitor General of Canada.

Hare RD (2006) Psychopathy: a clinical and forensic overview. Psychiatric Clinics of North America 29: 709-24.

Harkins L, Beech AR, Goodwill AM (2010) Examining the influence of denial, motivation, and risk on sexual recidivism. Sexual Abuse: A Journal of Research and Treatment 22: 78-94.

Hart SD, Kropp PR, Laws DR, et al (2003) Risk for Sexual Violence Protocol (RSVP). Mental Health, Law and Policy Institute, Simon Fraser University.

Hart SD, Boer DP (2010) Structured professional judgment guidelines for sexual violence risk assessment: The Sexual Violence Risk-20 (SVR-20) and the Risk for Sexual Violence Protocol (RSVP). In Handbook of Violence Risk Assessment (eds RK 0tto, KS Douglas): 269-94. Routledge.

Heil P, Simmons D (2008) Multiple paraphilias: etiology, assessment and treatment. In Sexual Deviance: Theory, Assessment and Treatment (2nd edn) (eds DR Laws, WT O'Donohue): 527-56. Guilford Press.
Heilbrun K, Yasuhara K, Shah S (2010) Violence risk assessment tools: overview and critical analysis. In Handbook of Violence Risk Assessment (eds RK Otto, KS Douglas): 1-17. Routledge.

Hill A, Habermann N, Berner W, et al (2007) Psychiatric disorders in single and multiple sexual murderers. Psychopathology 40: 22-8.

Home Office (2001) Prison Statistics England and Wales, 2001. TSO (The Stationery Office).

Home Office (2004) Home Office Statistical Bulletin: Crime in England and Wales 2003/04. Home Office Research and Statistics Department.

Hudson SM, Ward T (2000) Relapse prevention: assessment and treatment implications. In Remaking Relapse Prevention with Sex Offenders: A Source Book (eds DR Laws, SM Hudson, T Ward): 102-22. Sage.

Knight RA, Prentky RA (1990) Classifying sexual offenders: the development and corroboration of taxonomic models. In Handbook of Sexual Assault (eds WL Marshall, DR Laws, HE Barbaree): 23-52. Plenum Press.

Kocsis RN (2006) Criminal Profiling: Principles and Practice. Humana Press.

Langton CM, Barbaree HE, Harkins L, et al (2008) Denial and minimization among sexual offenders: posttreatment presentation and association with sexual recidivism. Criminal Justice and Behavior 35: 69-98.

Laws DR, Ward T (2011) Desistance from Sex Offending: Alternatives to Throwing Away the Keys. Guilford Press.

Malamuth NM, Sockloskie R, Koss MP, et al (1991) The characteristics of aggressors against women: testing a model using a national sample of college students. Journal of Consulting and Clinical Psychology 59: 670-81.

Malamuth NM, Heavey CL, Linz D (1996) The confluence model of sexual aggression: combining hostile masculinity and impersonal sex. Journal of Offender Rehabilitation 23: 13-37.

Mann RE, Hanson RK, Thornton D (2010) Assessing risk for sexual recidivism: some proposals on the nature of psychologically meaningful risk factors. Sexual Abuse: A Journal of Research and Treatment 22: 191-217.

Marshall WL, Barbaree HE (1990) An integrated theory of the etiology of sexual offending. In Handbook of Sexual Assault (eds WL Marshall, DR Laws, HE Barbaree): 257-75. Plenum Press.

Marshall WL (2002) Historical foundations and current conceptualizations of empathy. In In Their Shoes: Examining the Issue of Empathy and its Place in the Treatment of Offenders (ed YM Fernandez). Wood ' $\mathrm{N}$ ' Barnes Publishing

McSherry B, Keyzer P (2009) Sex Offenders and Preventive Detention. Politics, Policy and Practice. The Federation Press.

Ministry of Justice National Offender Management Service (2011) Working with Personality Disordered Offenders: A Practitioners Guide. Ministry of Justice.

Morin JW Levenson JS (2008) Exhibitionism - assessment and treatment. In Sexual Deviance: Theory, Assessment and Treatment (2nd edn) (eds DR Laws, WT O'Donohue): 76-107. Guilford Press.

Murphy WD, Page IJ (2008) Exhibitionism - psychopathology and theory In Sexual Deviance: Theory, Assessment and Treatment (2nd edn) (eds DR Laws, WT 0'Donohue): 61-75. Guilford Press.

Nunes KL, Hanson RK, Firestone P, et al (2007) Denial predicts recidivism for some sexual offenders. Sexual Abuse: A Journal of Research and Treatment 19: 91-105.

Olver ME, Wong SCP (2006) Psychopathy, sexual deviance, and recidivism among sex offenders. Sexual Abuse: $A$ Journal of Research and Treatment 18: 65-82.

Olver ME, Wong SCP (2011) A comparison of static and dynamic assessment of sexual offender risk and need in a treatment context. Criminal Justice and Behavior 38: 113-26.

Papps BP, O'Carroll RE (1998) Extremes of self-esteem and narcissism and the experience of anger and aggression. Aggressive Behavior 24: $421-38$
MCO answers

$1 \mathrm{~b} \quad 2 \mathrm{c} \quad 3 \mathrm{~d} \quad 4 \mathrm{~d} \quad 5 \mathrm{~d}$ 
Poortinga E, Newman SS, Negendank CE, et al (2009) Juvenile sexual offenders: epidemiology, risk assessment and treatment. In Sex Offenders: Identification, Risk Assessment, Treatment and Legal Issues (eds FM Saleh, AJ Grudzinskas, JM Bradford, et al): 221-40. Oxford University Press.

Proulx J, Beauregard E, Cusson M, et al (2007) Sexual Murderers: A Comparative Analysis and New Perspectives. John Wiley \& Sons.

Quayle E (2008) Online sex offending: psychopathology and theory. In Sexual Deviance: Theory, Assessment and Treatment (2nd edn) (eds DR Laws, WT O'Donohue): 439-58. Guilford Press.

Quinsey VL, Harris GT, Rice ME, et al (2006) Violent Offenders. Appraising and Managing Risk (2nd edn). American Psychological Association.

Raymond N, Coleman E, Ohlerking F, et al (1999) Psychiatric comorbidity in pedophilic sex offenders. American Journal of Psychiatry 156: 786-8.

Russell K, Darjee R (2012) Managing the risk posed by personality disordered sex offenders in the community: a model for providing structured clinical guidance to support criminal justice services. In Managing Clinical Risk: A Guide to Effective Practice (eds L Johnstone, C Logan): 88-114. Willan Publishing.

Sandler JC, Freeman NJ (2009) Female sex offender recidivism: a largescale empirical analysis. Sexual Abuse: A Journal of Research and Treatment 21: 455-73.

Smith A (1999a) Aggressive sexual fantasy in men with schizophrenia who commit contact sex offences against women. Journal of Forensic Psychiatry 10: 538-52

Smith AD (1999b) In-patient management of men with schizophrenia who commit serious sexual offences. Psychiatric Bulletin 23: 358-60.

Smith AD, Taylor PJ (1999c) Serious sex offending against women by men with schizophrenia. Relationship of illness and psychotic symptoms to offending. British Journal of Psychiatry 174: 233-7.

Smith AD, Taylor PJ (1999d) Social and sexual functioning in schizophrenic men who commit serious sex offences against women. Criminal Behaviour and Mental Health 9: 156-67.

Smith A (2000a) Motivation and psychosis in schizophrenic men who sexually assault women. Journal of Forensic Psychiatry 11: 62-73

Smith AD (2000b) Offence characteristics of psychotic men who sexually assault women. Medicine, Science and the Law 40: 223-8.
Stuker TS, Sporer SL (2002) When a grandiose self-image is threatened: narcissism and self-concept clarity as predictors of negative emotions and aggression following ego-threat. Journal of Personality 70: 509-32.

Thornton D (2003) The Machiavellian sex offender. In Sex Offenders in the Community: Managing and Reducing the Risks (ed A Matravers): 144-52. Willan.

Thornton D, Beech AR, Marshall WL (2004) Pretreatment self-esteem and posttreatment sexual recidivism. International Journal of Offender Therapy and Comparative Criminology 48: 587-99.

Thornton D (2007) Scoring Guide for Risk Matrix 2000.9/SVC. David Thornton. (http://www.bhamlive1.bham.ac.uk/Documents/college-les/ psych/RM2000scoringinstructions.pdf).

Vincent GM, Maney SM, Hart SD (2009) The use of actuarial risk assessment instruments in sex offenders. In Sex Offenders: Identification, Risk Assessment, Treatment and Legal Issues (eds FM Saleh, AJ Grudzinskas, JM Bradford, et al): 70-88. Oxford University Press.

de Vogel V, de Ruiter C, Bouman Y, et al (2009) SAPROF. Guidelines for the Assessment of Protective Factors for Violence Risk (English Version). Forum Educatief.

Ward T, Siegart RJ (2002) Toward a comprehensive theory of child sexual abuse: a theory knitting perspective. Psychology, Crime and Law 9: 319-51

Ward T, Polaschek DLL, Beech AR (2006) Theories of Sexual Offending. John Wiley \& Sons

Ward T, Beech AR (2008) An integrated theory of sexual offending. In Sexual Deviance: Theory, Assessment and Treatment (2nd edn) (eds DR Laws, WT O'Donohue): 21-36. Guilford Press.

Webster CD, Douglas KS, Eaves D, et al (1997) HCR-20: Assessing Risk for Violence (Version 2). Mental Health Law and Policy Institute, Simon Fraser University.

Webster SD, Mann RE, Cater AJ, et al (2006) Inter-rater reliability of dynamic risk assessment with sexual offenders. Psychology, Crime and Law 12: 439-52.

Wong SCP, Olver ME (2010) Two treatment- and change-oriented risk assessment tools: the Violence Risk Scale and Violence Risk Scale - Sex Offender Version. In Handbook of Violence Risk Assessment (eds RK Otto, KS Douglas): 121-46. Routledge.

\section{MCOs \\ Select the single best option for each question stem \\ 1 The rate of recidivism for a new sexual offence in sexual offenders over 5-10 years is about:
a $5 \%$
b $15 \%$
c $35 \%$
d $50 \%$ \\ e $65 \%$}

c RSVP

2 Which of the following is a structured professional judgement risk assessment instrument for sexual offending?

a HCR-20

b Static-99

\section{d Risk Matrix 2000}

e SORAG.

3 Which of the following is not an evidencebased risk factor for sexual recidivism:

a number of previous sexual offences

b sexual deviance

c antisocial personality disorder

d lack of victim empathy

e sexual preoccupation.

4 Sexual offending and mental illness:

a there is no epidemiological relationship

b delusions usually drive offending

c offences are usually bizarre d illness-related factors do not usually adequately explain offending

e having a mental illness is an important predictor of long-term recidivism.

\section{Stable dynamic risk factors for sexual} offending:

a are historical facts about the individual

b include victim access and deteriorating emotional state

c are proximal precipitants of sexual offences

d are psychological dispositions which may change slowly with time or treatment

e are not related to mental disorder. 